\title{
Uma reflexão sobre a emancipação humana pelo mundo do trabalho numa nova sociabilidade
}

\author{
A reflection on the world's human emancipation of work in a new sociability
}

\author{
Ângela Maria Moura Costa Prates*
}

\begin{abstract}
Resumo:
O trabalho é a categoria fundante do ser social, no seu processo de humanização na relação com a natureza. Nesse sentido, o presente artigo tem como objetivo discutir a emancipação humana e o mundo do trabalho na perspectiva da construção de uma nova sociabilidade. Em meio a correntes que defendem o fim da centralidade do trabalho, pensá-lo como imanente ao ser social no processo de preparação do solo para a revolução rumo a uma nova sociabilidade é instigante e desafiador. Conclui-se que a emancipação humana, na qual a liberdade reina plena, somente é possível numa outra sociabilidade, e o sujeito por excelência para alimentar o processo revolucionário para a construção dessa nova sociedade é a classe trabalhadora.
\end{abstract}

Palavras-chave: Emancipação humana. Trabalho. Nova sociabilidade.

\begin{abstract}
:
The work is a founding category of social being, in the process of its humanization in the relationship with nature. In this sense, the present article aims to discuss human emancipation and the world of work in the perspective of building a new sociability. Amid the current advocating the end of the centrality of work, think of it as immanent to the social being in the process of preparing the ground for the revolution towards a new sociability is exciting and challenging. We conclude that human emancipation, where freedom reigns full is only possible in another sociability, and the subject as excellence to feed the revolutionary process for building this new society is the working class.
\end{abstract}

Key-Words: Human emancipation. Work. New sociability.

"Os filósofos limitaram-se a interpretar o mundo de diversas maneiras; o que importa é modificá-lo" (Karl Marx).

\section{Introdução}

\footnotetext{
- Universidade Federal de Santa Catarina (UFSC). Assistente Social pela Universidade Estadual do Centro Oeste (UNICENTRO); Especialista em Formação de Professores para a Docência no Ensino Superior também pela Unicentro; Mestre em Ciências Sociais Aplicadas pela Universidade Estadual de Ponta Grossa (UEPG) e Doutoranda em Serviço Social pela Universidade Federal de Santa Catarina (UFSC). E-mail: pratesammc@gmail.com
} 
Não é possível pensar a possibilidade da emancipação humana sem conectá-la ao mundo do trabalho. Entre crises e metamorfoses, o trabalho tem sido alvo de discussões teóricas das mais variadas, sendo uma delas a defesa do fim de sua centralidade. Entretanto, o crescimento do desemprego, a troca do trabalhador pelas máquinas devido ao desenvolvimento tecnológico trazido pela modernidade não podem sustentar a ideia do fim da sua centralidade, pois apesar das crises capitalistas ter diminuído o trabalho vivo, não pode eliminá-lo. Isso também é discutido em outras correntes, as quais associam a constituição do ser social enquanto tal ao trabalho, assim como interliga a possibilidade da emancipação humana também a ele - trabalho associado - o qual só é possível de ser realizado numa nova sociabilidade, sugerida pelos autores como comunismo.

Nesse sentido, o objetivo deste trabalho é discutir a emancipação humana e o mundo do trabalho na perspectiva da construção de uma nova sociabilidade. As reflexões trazidas aqui partiram das discussões teóricas empreendidas na Disciplina Tópicos especiais em Trabalho e Questão Social do Programa de Pós-Graduação em Serviço Social (PPGSS) da Universidade Federal de Santa Catarina (UFSC) ofertada no segundo semestre de 2012.

$\mathrm{Na}$ era das comunidades primitivas não havia diferença social. O que as comunidades produziam era igualmente repartido entre todos. É certo que não havia também tecnologias e nada do que se tem hoje na pós-modernidade, mas também não havia a exploração do homem pelo homem. Paulo Netto e Braz (2007) chamam essas comunidades de 'comunismo primitivo'. Elas existiram por mais de trinta mil anos, mas foram se dissolvendo por dois motivos: "[...] a domesticação de animais e o surgimento da agricultura" (PAULO NETTO; BRAZ, 2007, p. 56). Aos poucos, uma comunidade começou a se sobressair a outra e se iniciou certo controle do tempo, das trocas, e principalmente houve mudanças com relação à produtividade. Uma mudança foi significativa sobremaneira: "A principal transformação, porém, residiu no fato de, nessas comunidades, os resultados da ação do homem sobre a natureza permitirem uma produção de bens que ultrapassava as necessidades imediatas da sobrevivência dos seus membros" (PAULO NETTO; BRAZ, 2007, p. 57). Com isso, estava surgindo o que os autores chamam de 'excedente econômico'. Foram as primeiras experiências de acumulação de riquezas. Para isso, era necessário explorar os trabalhadores. Desde então, a sociedade foi passando por vários regimes, como escravidão, feudalismo e atualmente o capitalismo. Nesses regimes 
todos, houve a exploração do homem pelo homem, argumenta Tavares (2009). "No escravismo e no feudalismo, a exploração tinha limites biológicos, porque o homem era um meio de produção. Na sociedade capitalista, a vida do trabalhador não impõe limites à produção" (TAVARES, 2009, p. 240). O capitalismo foi se renovando ao longo do tempo e acirrando a exploração da classe trabalhadora. De crise em crise, o ônus sempre ficou para o trabalhador. O que se tem hoje não é o trabalho enquanto manifestação do homem numa dimensão de satisfação com a construção de seus produtos, mas um sujeito esmagado pela extração de mais-valia, alienado do processo de produção como um todo e com raras perspectivas de emancipação por meio do trabalho. Apesar disso, o que se quer neste texto é recuperar o argumento do trabalho enquanto categoria fundante do ser social primordial ao processo de construção de uma nova sociabilidade rumo à emancipação humana.

\section{O trabalho como categoria fundante do ser social e o debate sobe o fim da sua centralidade}

Antes de pensar se é possível acabar com a exploração do homem pelo homem é preciso saber que o ser social é radicalmente histórico, como histórica é também a realidade social. A essência do ser enquanto tal é fruto da interatividade humana. Portanto, a realidade na qual ele está inserido é uma totalidade que é o conjunto de partes articuladas e em processo, mas que tem uma única matriz. A relação entre a consciência e a realidade objetiva junta indivíduos e gênero humano do qual o ser social é composto (CANIELLES; OLIVEIRA, 2011; FORTES, 2009; LESSA, 1997; PAULO NETTO; BRAZ, 2007).

O pensamento de Georg Lukács trata da ontologia do ser social. Ele não isola determinada categoria para precisar o ser social, mas usa o trabalho que já contém em si um complexo todo articulado. O homem é um ser que se faz sempre numa posição subjetiva, a qual só se dá em relação à objetividade. Ele se torna humano no meio dos humanos, por meio da sociabilidade, da linguagem e da teleologia. A ontologia do ser social supõe a relação dele com a natureza. Lessa (1997), um estudioso de Lukács apresenta três formas de seres, sendo: o ser inorgânico, o ser orgânico e o ser social. No primeiro, não há vida e diz respeito ao mundo mineral. "O ser inorgânico, acima de tudo, não possui vida. Seu processo de transformação, sua evolução, nada mais é senão um movimento pelo qual algo se transforma em um outro algo distinto" (LESSA, 1997, p. 14). Já a segunda esfera do 
ser é a orgânica, em que há a recolocação desse por um processo natural. "O mero recolocar do mesmo que caracteriza a reprodução biológica, ou o tornar-se outro da esfera inorgânica [...]" (LESSA, 1997, p. 14). O autor ressalta que em ambos o processo acontece de forma natural sem que haja planejamento de nada. Diferente do ser social que, como a história de Ikursk, o homem é capaz de obter na consciência algo que vai fazer posteriormente, ou seja, é capaz de criar um processo de ideação. E isso o diferencia dos demais seres, numa distinção ontológica.

Enquanto no ser social a consciência joga um papel fundamental, possibilitando que os homens respondam de maneira sempre nova às novas situações postas pela vida, na trajetória da goiabeira a sua reprodução apenas é possível na absoluta ausência da consciência (LESSA, 1997, p. 16).

De acordo com Paulo Netto e Braz (2007, p. 34), o ser humano tornou-se ser social por meio do trabalho, "[...] numa espécie de salto que fez emergir um novo tipo de ser, distinto do ser natural [...]: o ser social”. Por isso, Lessa (1997) mostra a distinção entre os seres. Para ele,

De modo análogo, entre o ser biológico e o inorgânico temos, também, uma distinção ontológica: o tornar-se-outro da pedra é uma forma distinta de ser do repor-o-mesmo da goiabeira. A pedra não se reproduz, enquanto que a goiabeira só pode existir enquanto permanente processo de reprodução de si mesma (LESSA, 1997, p. 16).

Assim, o ser social se reproduz na sua relação com a natureza numa dimensão teleologicamente posta. Paulo Netto e Braz (2007) apontam que as necessidades humanas são satisfeitas numa relação entre o homem e a natureza. "[...] a sociedade, através de seus membros homens e mulheres, transforma matérias em produtos que atendem as suas necessidades. Essa transformação é realizada através da atividade a que denominamos trabalho" (PAULO NETTO; BRAZ, 2007, p. 30). O homem é diferente dos animais. Estes realizam atividades na natureza, também para satisfazer as suas necessidades, porém, por instinto. O ser humano constitui-se enquanto ser social por meio do e no trabalho, em sua relação com a natureza. Relacionando-se com a natureza, os seres formam uma unidade inseparável e toda articulada.

Em poucas palavras, a unidade última do ser não é destruída pela gênese e pelo desenvolvimento das três esferas ontológicas. Pelo contrário, com a gênese e o 
desenvolvimento da vida e do ser social, a unidade é mantida num patamar mais elevado, ganha novos matizes e se torna mais rica e articulada (LESSA, 1997, p. 18).

Essa diferença entre os seres inorgânicos, orgânicos e o ser social se dá justamente porque o homem é capaz de criar um processo de ideação e isso se dá por meio do trabalho. Para Paulo Netto e Braz (2007), essa atividade chamada trabalho é completamente diferente daquelas que os animais realizam por três motivos: primeiro "[...] o trabalho não se opera com uma atuação imediata sobre a matéria natural [...]", depois, ele "[...] não se realiza cumprindo determinações genéticas [...]", e, por fim, ele "[...] não atende a um elenco limitado e praticamente invariável de necessidades [...]" (PAULO NETTO; BRAZ, 2007, p. 31). A relação que se dá no trabalho é uma relação entre um sujeito - o ser social - e o seu objeto - a natureza orgânica e inorgânica. O humano é o mediador por excelência desse processo relacional entre sujeito e objeto.

Outro aspecto que diferencia o homem dos demais seres é a sua capacidade de criar instrumentos de trabalho. Por meio destes, o ser social produz os meios para a sua sobrevivência, primeiramente na sua consciência e depois na prática. Por exemplo: somente o ser humano é capaz de produzir em sua mente um instrumento de trabalho ou outro objeto qualquer, para depois materializá-lo. Vale lembrar que o trabalho constitui o ser social, mas este não pode ser reduzido apenas ao trabalho. Quando Lukács fala em complexo do trabalho, ele está fazendo uma abstração. Para ele, o trabalho pertence ao homem, diferente dos animais.

O 'pôr teleológico' é a categoria central do trabalho, pois por meio dele uma posição teleológica se realiza no âmbito do ser material como nascimento de uma nova objetividade (TERTULIAN, 1996). Para ele, o trabalho vai caracterizar toda a atividade humana. Nesse sentido, o trabalho não é o foco, mas o pôr teleológico que se dá numa relação com a natureza, homem e sociedade (FORTES, 2009). Assim, os homens têm 'pores' teleológicos nas relações entre si. Esse pôr teleológico só pode se dar por meio do trabalho, porque os outros complexos já existem como categorias sociais puras. É na natureza que se encontram as categorias que levam o homem a saltá-la. Para Fortes (2009), todo ato de decisões humanas é um ato de decisão entre alternativas, portanto, é um pôr teleológico. Na relação objetividade/subjetividade, a última é livre para escolher entre alternativas postas pela objetividade. Portanto, na concepção de Fortes (2009), o trabalho não é 
central, pois central são os pores teleológicos revelados nas práticas sociais. Para o autor, em vez de se falar em centralidade do trabalho é melhor falar em momento preponderante, que é a produção. Nesse sentido, Fortes (2009) coloca a centralidade em lugar diferente de Lessa (1994). Resumindo, para Fortes (2009) a centralidade é do pôr teleológico, já para Lessa $(1994 ; 1996)$ a centralidade é do trabalho.

O mundo do trabalho na atualidade vem sofrendo profundas transformações, as quais Antunes (2000) chamou de metamorfoses. Essas mudanças no mundo do trabalho estão relacionadas às mesmas mudanças na dinâmica do capitalismo recente (ANTUNES; SILVA, 2004), que deixa o ônus para a classe trabalhadora.

Diante de tantas transformações, há correntes teóricas que apontam para o fim da centralidade do trabalho. Mas, mediante o exposto, como fica o ser social diante dos argumentos que apontam para o fim da centralidade do trabalho? Atualmente, existe o pressuposto de que se perdeu a centralidade do trabalho, da política do trabalho, e dele como processo revolucionário (TONET, 2010). Essas três questões se perderam, tanto do ponto de vista teórico quanto político. Junto com essas três questões também se perdeu a centralidade da objetividade, isso do ponto de vista metodológico. Objetividade é aqui a existência da realidade objetiva, da materialidade. Também se perdeu, ainda, a perspectiva de uma forma de sociabilidade plenamente livre, em que os seres humanos sejam efetivamente protagonistas de sua história. Essa plenitude saiu do horizonte. Isso ficou comprovado por meio das revoluções que fracassaram. Nesse sentido, o reformismo foi ganhando espaço. Mudar o mundo passou a ser utopia, mas mudar radicalmente o mundo parece impossível (TONET, 2010).

Um dos argumentos que sustenta o fim da centralidade do trabalho parte de Offe (1989a; 1989b; 1991). Ricardo Antunes, um estudioso do trabalho, discorda disso. Ele aponta que há atualmente uma redução do trabalho abstrato, mas isso não lhe tira o papel fundamental na criação de valores de troca. Mesmo que tenha havido uma redução do tempo físico, do trabalho manual, ampliando para uma dimensão mais intelectualizada, não se tem como negar a lei do valor "[...] quando se considera a totalidade do trabalho, a capacidade de trabalho socialmente combinada, o trabalhador coletivo como expressão de múltiplas atividades combinadas" (ANTUNES, 2011, p. 1). Para o autor, existe uma crise do 
trabalho abstrato, mas essa só pode ser entendida como "[...] a redução do trabalho vivo e a ampliação do trabalho morto" (ANTUNES, 2011, p. 1).

A sociedade do capital precisa cada vez menos do trabalho estável e cada vez mais intensivamente do trabalho terceirizado, precarizado, informal e mal remunerado. Isso só prova que "[...] o capital não pode eliminar o trabalho vivo do processo de criação de valores, ele deve aumentar a utilização e a produtividade do trabalho de modo a intensificar as formas de extração do sobretrabalho em tempo cada vez mais reduzido". (ANTUNES, 2011, p. 4). O capital precisa do trabalho, logicamente mais do trabalho intelectual, quando se trata de maquinarias. A máquina não tem capacidade de se autossustentar. Para que ela funcione, é necessário um ser pensante que dirija as suas funções. "A transferência de capacidades intelectuais para a maquinaria informatizada, que se converte em linguagem da máquina própria da fase informacional, através dos computadores, acentua a transformação de trabalho vivo em trabalho morto". (ANTUNES, 2011, p. 8). Não se pode pensar na extinção do trabalho enquanto aquele que rege a sociedade do capital e enquanto aquele que cria valores de uso para o ser social em sua relação com a natureza, pois:

[...] uma coisa é conceber, com a eliminação do capital e de seu sistema de metabolismo social, o fim do trabalho abstrato, do trabalho estranhado e alienado; outra, muito distinta, é conceber a eliminação, no universo da sociabilidade humana, do trabalho concreto, que cria coisas socialmente úteis e que, ao fazê-lo, (auto)transforma o seu próprio criador (ANTUNES, 2011, p. 6).

Antunes (2011) aposta no tempo livre como aquele que será capaz de resgatar o sentido da vida ao ser social. Esta forma somente é possível no trabalho associado, em que o sujeito, “[...] ética, arte, filosofia, tempo verdadeiramente livre e ócio, em conformidade com as aspirações mais autênticas, suscitadas no interior da vida cotidiana, possibilitem as condições para a efetivação da identidade entre indivíduo e gênero humano, na multilateralidade de suas dimensões (ANTUNES, 2011, p. 11). No trabalho associado, os sujeitos poderão eliminar as barreiras entre tempo de trabalho e tempo livre, e poderão realizar atividades cheias de sentido que recobrem a satisfação do homem com o produto de sua produção. 
E o empreendimento societal por um trabalho cheio de sentido e pela vida autêntica fora do trabalho, por um tempo disponível para o trabalho e por um tempo verdadeiramente livre e autônomo fora do trabalho - ambos, portanto, fora do controle e comando opressivo do capital - convertem-se em elementos essenciais na construção de uma sociedade não mais regulada pelo sistema de metabolismo social do capital e seus mecanismos de subordinação (ANTUNES, 2011, p. 11).

Antunes (1999) defende que o trabalho continua sendo a categoria central na constituição do ser social, porque a sociabilidade, a linguagem, assim como a primeira divisão do trabalho fazem parte do ato laborativo. Assim, de acordo com o autor "O trabalho constitui-se como categoria intermediária que possibilita o salto ontológico das formas pré-humanas para o ser social" (ANTUNES, 1999, p. 136). Nesse sentido, o trabalho faz parte do processo de humanização do homem, pois por meio dele "[...] o ser social cria e renova as próprias condições da sua reprodução" (ANTUNES, 1999, p. 136). Para o autor, é o trabalho a categoria central porque é por meio dele "[...] uma posição ontológica é realizada no interior do ser material, como nascimento de uma nova objetividade" (ANTUNES, 1999, p. 136-137). A partir daí o trabalho passa a ser a protoforma de toda práxis social, argumenta o autor.

Para os autores que apostam na centralidade do trabalho na constituição do ser social, não se pode dar margens às argumentações sobre o seu fim, embora o capitalismo tenha reconfigurado o trabalho, tornando-o apenas força de trabalho - mercadoria - a ser explorada para fins de extração máxima de mais-valia. Para Granemann (2009, p. 235), "Condenar o trabalho produtor de valor excedente ao desaparecimento equivale a banir, a superar o capital como organizador de uma certa sociabilidade, aquela diferenciada na mercadoria". É o trabalho que produz toda a riqueza consumida pelas classes. É por ele que o capital pode continuar o seu giro na busca desenfreada por mais lucro. Para Granemann (2009, p. 235):

[...] o que se quer validar com as teses declaratórias de que o trabalho chegou ao fim é uma velha, mas nem por isto menos vital, e contemporânea questão: a reprodução das relações sociais no modo de produção capitalista está caucionada na riqueza fertilizada pelo trabalho não pago. Suprimi-lo é cancelar a sociabilidade característica do modo capitalista de produção. Tarefa primordial e plena de atualidade para os trabalhadores. 
Mediante as discussões expostas anteriormente, vem uma incógnita: é possível construir uma sociabilidade nova, onde não haja exploração do homem pelo homem e estes sejam plenamente livres? É o que será discutido a seguir.

\section{A emancipação humana numa nova sociabilidade}

A ideia de emancipação teve uma forte conotação na modernidade, na qual se defendia a liberdade de racionalidade humana, liberdade de pensar e exercer a racionalidade. $O$ conhecimento da natureza era uma forma de dominá-la. Emancipar-se era pensar livremente e não pensar com a cabeça da $\operatorname{Igreja}^{1}$ e do poder político. Por isso, chamou-se de iluminismo. Na medida em que pensavam, poderiam conhecer a natureza e dominá-la (ARANHA; MARTINS, 1998). Portanto, a ideia de emancipação está associada ao progresso, pois enfatiza a subjetividade. É como se à medida que as pessoas quisessem pensar livremente, assim o fariam. Nesse aspecto, a conscientização das pessoas mudaria a realidade. Isso é corrente quando se pensa nos programas e políticas sociais.

Neste trabalho, é o viés marxista que vai iluminar a compreensão da categoria emancipação, inaugurado por Marx e resgatado por Lukács. De acordo com Tonet (2005), a emancipação humana somente é possível numa outra sociedade, que não a capitalista. Essa outra sociedade ele sugere que seja o comunismo, sob outro nome. Em todo caso, uma nova sociabilidade onde haja plena liberdade. E para Canielles e Oliveira (2011, p. 7):

A emancipação humana está no horizonte de toda a produção de Marx, é o principio pelo qual haveria a possibilidade de rompimento e superação do modelo social do capital e a possibilidade de instauração de um novo modelo social em que acabaria com a dualidade do homem na sociedade.

A crítica da emancipação política começou com a Questão Judaica de Marx (1991). A Questão Judaica é uma crítica da natureza da emancipação política. Nesse momento, ele já chegara à conclusão de que o trabalho era a categoria fundante. No sistema feudal, o poder político e o econômico residia numa mesma pessoa. Por incompatibilidade, os judeus não possuíam direitos políticos, em que o cerne da antítese era a religião.

\footnotetext{
${ }^{1}$ Igreja aqui faz menção à Igreja Católica Apostólica Romana que durante muitos séculos deteve o controle e a posse da produção do conhecimento.
} 
Nesse texto, Marx (1991) discutiu o caráter religioso do Estado. Bauer propõe uma discussão teleológica do Estado a qual Marx desmonta. A questão teológica da Questão Judaica é: por que o Estado é religioso? Marx faz uma desconstrução interna para depois fazer a sua própria crítica. De acordo com Canielles e Oliveira (2011, p. 3):

\begin{abstract}
Assim, Marx adverte que a emancipação buscada por Bauer tem caráter restrito e unilateral, por referir-se unicamente ao Estado Cristão, e não ao Estado Geral. Falta-lhe, ainda, a diferenciação entre emancipação política e emancipação humana, bem como a problematização acerca dos interesses individuais e coletivos dos homens na sociedade.
\end{abstract}

De acordo com os autores, Marx faz uma diferenciação entre emancipação política e humana. Para Marx, a essência da religião não se opõe ao estado judaico, então ele faz a crítica ao estado enquanto tal, partindo da religião para depois ir para a propriedade privada, para enfim chegar à questão da emancipação.

Para Marx (1991), a consciência é dada pela realidade, portanto, é produto histórico. Assim, o homem reflete o mundo dos homens. É a vida que constrói a consciência. Essa não é pura abstração, não é previa. A consciência nunca foi sequestrada. É ela que diferencia os homens dos animais (MARX, 1971). O homem enquanto ser social está envolto em vários elementos, como razão, imaginação e trabalho. É isso que o diferencia dos animais, porque ele é capaz de articular esses elementos, constituindo-se enquanto homem (PAULO NETTO; BRAZ, 2007). O processo de alienação que Marx tanto fala ataca esses elementos ofuscando a natureza do ser social. Nela o homem não se reconhece no próprio trabalho.

A liberdade política não se confunde com a liberdade. O estado expulsou-a da própria esfera quando se institucionalizou, pois é o estado que emoldura as lutas, quando deveria ser o contrário. Ele toma as diferenças como não diferenças. A crítica de Marx (1991) está na transcendentalização do Estado, em que ele é o maestro. Todo Estado faz a ideia de um povo hegemônico, onde não há diferenças. Vale ressaltar que qualquer processo que isenta o ser de elementos políticos resulta num processo de autoalienação. Por isso, Marx (1991) denuncia toda discussão sobre política, desprovida da economia, da cultura e vice-versa.

No entanto, é pouco a emancipação política. Necessário mesmo é a emancipação humana, argumenta Marx. Agora, o problema é o lugar onde se coloca a emancipação 
humana, no estado. Para Marx (1991), não se tem saída possível para a emancipação humana pela via do Estado.

O tema da emancipação na contemporaneidade constitui-se corriqueiro, principalmente quando se trata das políticas sociais. ${ }^{2}$ Nos discursos, qualquer atividade, mesmo emergencial, trata da emancipação. Mas emancipar de quê? De que tipo de emancipação se está falando? O que se está entendendo por emancipação?

O processo histórico se dá ao redor do embate entre as classes fundamentais, burguesia e proletariado, em que a última produz toda a riqueza para a primeira apropriarse dela. A teoria liberal diz que os homens são iguais por natureza. É da natureza dele ser livre e egoísta (TONET, 2010). Porém, se a natureza humana é assim, a sociabilidade atual é própria para o homem. A sociedade burguesa afirma que o homem é igual e egoísta, acredita que a desigualdade é resultado dessa igualdade. Pois, "[...] a noção de liberdade no liberalismo, que ele reputa de caráter universal, nada mais é do que a liberdade do individuo entendido como naturalmente proprietário privado e que, como tal, tem em si o eixo da sua realização" (TONET, 2010).

Para pensar na emancipação, é necessário que haja a maturidade do ser social. “Um dos elementos importantes dessa maturidade é também o amadurecimento das duas classes - burguesia e trabalhadora - que serão responsáveis ontológicas pela emergência de dois projetos antagônicos de sociedade" (TONET, 2010). Max elaborou essa nova perspectiva devido a sua articulação, sua vivencia em meio à classe trabalhadora. A primeira questão para a possibilidade da emancipação humana seria um alto desenvolvimento das forças econômicas. Não é possível emancipação sem que a humanidade tenha desenvolvido as forças produtivas, ou seja, a capacidade humana de produzir riquezas, a fim de satisfazer as necessidades de todos.

Desde o capitalismo, com a sua lógica da propriedade privada e da acumulação, a humanidade se transformou, pois perdeu o controle de sua produção, como faziam na era primitiva. "Aquelas forças, que eram sociais ao longo de todo o processo produtivo, foram

\footnotetext{
2 Para exemplificar: A Política de Assistência Social fala em emancipação do sujeito em situação de vulnerabilidade social. Vale ressaltar que o conceito de emancipação de que trata a política é diferente do conceito de emancipação discutido pela teoria marxista. Para a Assistência Social emancipar significa incluir o sujeito no mercado de trabalho, mesmo que informal ou na forma de empreendedorismo, para que esse possa adquirir minimamente as condições básicas de sobrevivência. Também, emancipar-se significa para a política acessar os direitos básicos de cidadania.
} 
privatizadas, isto é, separadas do controle dos produtores e colocadas a serviço dos interesses de uma parte da sociedade, uma pequena minoria" (TONET, 2010, p. 5). Segundo o autor, o controle dessas forças é fundamental para se manter a propriedade privada. Neste sentido, a retomada do controle dessas forças são essenciais para se pensar uma nova sociabilidade onde não haja a exploração do homem pelo homem. Para ele, essa sociedade nova é a sociabilidade comunista.

O capitalismo necessariamente tem que conviver com a escassez e destruir as forças produtivas para obter mais lucro. É preciso que haja bens materiais para atender às necessidades de todos e não apenas de alguns. O desenvolvimento das forças produtivas é o desenvolvimento das potencialidades humanas. Todo o desenvolvimento atual é contrário à emancipação humana. As máquinas não são feitas para atender às necessidades humanas, mas para atender às perspectivas do lucro para o valor de troca. Hoje a máquina controla o trabalhador. Na sociedade comunista, os trabalhadores controlariam as máquinas de forma associada, livre e coletiva (TONET, 2010). Trabalho é autoatividade à medida que constrói o ser humano, constrói a sua subjetividade, construindo a si mesmo. O homem não faz atividade. Ele é atividade à medida que resulta dela. A essência humana é o conjunto das relações sociais.

Para Tonet (2010), o autodesenvolvimento das forças produtivas somente são possíveis mediante a apropriação das forças produtivas por parte do proletariado. A humanidade é um ente universal. Por isso, as forças produtivas devem ter um caráter universal. O homem precisa desenvolver a capacidade de apropriar-se da maquinaria. Isso só pode ser realizado por meio de uma união universal, uma revolução. Esse conjunto de coisas podem levar os trabalhadores a tomarem o controle das forças produtivas. É o conjunto dos trabalhadores que devem exercer livre, coletiva e universalmente as forças produtivas.

Para ser possível a emancipação humana, não basta que o trabalho seja a categoria fundante. O capitalismo não vai morrer por si. E, nesse sentido, o comunismo não é um desdobramento do capitalismo. Para se construir uma nova sociabilidade, é preciso criar um processo de objetivação, consciente e prático. De acordo com Tonet (2010, p. 1), “A luta da classe trabalhadora pela sua emancipação e de toda a humanidade implica o conhecimento, o mais amplo e profundo possível, da realidade social a ser transformada". 
A centralidade política do trabalho é a capacidade que os trabalhadores têm de dirigir o processo revolucionário. "Essa forma nova de apropriação das forças produtivas é que Marx chama de trabalho associado" (TONET, 2010, p. 6).

Assim, a categoria trabalho associado é fundamental para pensar a emancipação humana, pois ainda de acordo com Tonet (2010), existe íntima relação entre trabalho associado e revolução. A essência da revolução é uma mudança na forma de trabalho, na substituição do trabalho alienado pelo trabalho associado. A revolução proletária é uma revolução política com alma social. Todas as revoluções foram de cunho político, que mexeram no estado e no trabalho, mas não aboliram a exploração do homem pelo homem, da propriedade privada e da desigualdade social.

Contemporaneamente, perdeu-se a centralidade do trabalho. Atribui-se às cooperativas o trabalho associado, porém isso não se configura verdade. $O$ trabalho associado é uma forma de trabalho no qual os trabalhadores controlam o processo de trabalho de forma livre, consciente, coletiva e universal. "Sabe-se que, do ponto de vista marxista, o controle dos meios de produção é a questão chave para definir o caráter de uma forma de sociabilidade" (TONET, 2010, p. 3), ou seja, está fora da lógica do capital. Ele é o fundamento da sociabilidade comunista e da emancipação humana.

Marx caracteriza a emancipação humana como uma associação entre o reino da liberdade e o reino das necessidades humanas. Para Marx, trabalho associado é ainda o reino das necessidades, embora seja a forma mais humana de trabalho. Isso porque só pode existir liberdade se existir tempo livre. "Por isso é que a pedra angular do modo de produção comunista é o trabalho associado, uma forma radicalmente nova de intercambio do homem com a natureza e adequada a esta nova forma de sociabilidade" (TONET, 2010, p. 6).

O trabalho associado possui quatro características que o identificam apontadas por Tonet (2010). A primeira delas é a liberdade. Os indivíduos livres e conscientes de suas decisões fazem intercâmbio com a natureza para produzir materiais de subsistência para a satisfação de suas necessidades e de todos. "Embora sujeitos às leis da natureza, são eles que decidem, partindo de suas necessidades, o que deve ser produzido e como deve ser repartido o fruto de seu trabalho" (TONET, 2010, p. 7). Neste aspecto, valor de uso e trabalho associado são inseparáveis. 
A segunda característica do trabalho associado é que ele é realizado por sujeitos conscientes. Eles têm consciência de todo o processo de produção de seus bens e da divisão deles entre os seus. E também não há “[...] nem a 'mão invisível' do mercado, nem a lógica da reprodução do capital, nem qualquer teleologia que não seja aquela determinada pelos próprios sujeitos desse processo" (TONET, 2010, p. 7).

A terceira característica é a coletividade. Os sujeitos realizam as atividades de produção de forma coletiva, em que todos acompanham todo o processo, desde a escolha pelo que produzir, a forma de produzir, a distribuição e também o consumo. "Trata-se, hoje, de retirar essas forças sociais multiplicadas da submissão a poderes privados e restituí-las aos seus verdadeiros donos, isto é, aos produtores. Essa restituição é tarefa do trabalho associado" (TONET, 2010, p. 7-8). E ainda de acordo com Canielles e Oliveira $(2011$, p. 7) “[...] a emancipação humana só é possível quando o homem individual for superado e, coletivamente, determinar-se como ser genérico". Mas, para isso, os autores argumentam que é preciso a formação de uma nova consciência política e social da classe trabalhadora, a qual é a classe por excelência que busca a emancipação.

A quarta característica refere-se ao caráter universal do trabalho associado. Tonet (2010) descarta qualquer possibilidade da construção de uma nova sociabilidade, a comunista, em apenas um país. A revolução pode começar com países menos desenvolvidos, mas tem de se universalizar. O problema das revoluções foi que não conseguiram ampliar para os demais países (HOBSBAWM, 1995). E, portanto, não atingiram o coração do capital. Toda vez que uma tentativa revolucionária não conseguia universalizar, a exploração do homem pelo homem foi se recompondo. Mas, o máximo que pode acontecer foi um constrangimento ao capital. Num processo de transição tem que haver formas de trabalho que levem ao trabalho associado, porque este só entra em cena no comunismo. Portanto, "Uma humanidade comunista será uma comunidade universal, sem que isso implique a supressão da diversidade, ou não será comunista" (TONET, 2010, p. 8). Para que haja o trabalho associado, é necessário que haja uma reestruturação dos instrumentos de trabalho também. Mas, a questão mais importante é que jamais o controle de todo o processo de trabalho escape dos seus donos, os trabalhadores.

\section{Considerações finais}


A proposta inicial era a de discutir a emancipação humana e o mundo do trabalho na perspectiva da construção de uma nova sociabilidade, onde a liberdade reine plena e onde não haja exploração do homem pelo homem.

As protoformas do capitalismo tiveram início quando as comunidades primitivas descobriram formas de controlar o tempo no processo de produção e, também, quando perceberam que quem produzisse mais teria mais mercadorias para trocar, estando, nesse caso, em vantagem diante das demais comunidades. Paulo Netto e Braz (2007) afirmam que nisso nasceu o germe das desigualdades sociais, e, principalmente, quando os homens produziram bens para além da satisfação de suas necessidades básicas de sobrevivência.

Com o passar dos séculos, de crise em crise, o capitalismo foi se reconfigurando e tomando formas como a que se tem atualmente. É um sistema mundializado, financeirizado, fetichizado e altamente competente na extração da mais-valia absoluta e relativa. O trabalho, fundante do ser social, responsável por toda a produção de riquezas é tomado pela alienação. Portanto, de acordo com os autores estudados neste texto, não é possível romper com ele no capitalismo atual, mas é possível plantar e cultivar o germe de uma nova sociabilidade onde o trabalho seja associado. Assim, percebeu-se que a classe trabalhadora é o sujeito por excelência para preparar o solo para a revolução, para que quando o momento chegar ele possa ser perceptível aos trabalhadores. Para isso, ela precisa erradicar toda a exploração do homem pelo homem, a qual é da natureza da relação capital e trabalho. Tonet (2005) argumenta que essa é uma demanda da classe trabalhadora, independentemente de sua consciência.

O capitalismo não vai morrer por si só. Por isso, é preciso retomar a centralidade política do trabalho, na qual os trabalhadores sejam capazes de dirigir o processo revolucionário. Assim, a essência da revolução é uma mudança na forma de trabalho, quando se substitui o trabalho alienado pelo associado. No trabalho associado, os trabalhadores controlam, livre, coletiva e universalmente as forças produtivas. Para isso, é necessário que os trabalhadores providenciem a destruição do poder político da burguesia, pois o instrumento político de sua escravização não pode ser o mesmo de sua libertação.

Por mais que existam correntes que afirmem o fim da centralidade do trabalho, não se pode aceitar isso como verdade, uma vez que a sociedade capitalista ainda vive do trabalho e precisa dele para produzir riquezas. O desenvolvimento tecnológico não foi 
capaz de eliminar o ser pensante que se esconde atrás da maquinaria. Elas podem até tomar um número significativo de postos de trabalho, mas não podem administrar o trabalho intelectual, o qual só é possível no trabalho vivo. Percebeu-se que as mudanças vividas pela classe trabalhadora a partir das crises do capitalismo não diminuíram a necessidade do trabalho vivo, pelo contrário, houve acirramento da exploração da força de trabalho. Como afirma Antunes (2001), pode-se até diminuir o trabalho vivo, mas não eliminá-lo.

Diante das discussões anteriores, fica a questão: É possível que os seres humanos sejam totalmente livres? Conclui-se que a emancipação humana, em que a liberdade reina plena, somente é possível numa outra sociabilidade, e o sujeito por excelência, para alimentar o processo revolucionário para a construção dessa nova sociedade, é a classe trabalhadora. A revolução não vai acontecer como num passe de mágica ou por osmose. Ela precisa ser gestada, construída e alimentada pelos trabalhadores. Nessa nova sociabilidade não haverá a exploração do homem pelo homem, não haverá alienação e nem classes. O trabalho será associado e todos os trabalhadores usufruirão das riquezas produzidas por eles para satisfazer as necessidades básicas de todos.

\section{Referências}

ANTUNES, R. Adeus ao trabalho? Ensaio sobre as metamorfoses e a centralidade do mundo do trabalho. 7. ed. São Paulo: Cortez, 2000.

. Os sentidos do trabalho: ensaio sobre a afirmação e a negação do trabalho. São Paulo: Boitempo, 1999.

. Trabalho e precarização numa ordem neoliberal. In: FRIGOTTO, G.; GENTILI, P. (Org.). A cidadania negada: políticas de exclusão na educação e no trabalho. São Paulo: Cortez, 2001. p. 35-48.

2011.

. O trabalho e seus sentidos. Revista Debate \& Sociedade, Uberlândia, v. 1, n. 1,

ANTUNES, R.; SILVA, M. A. M. (Org.). O avesso do trabalho. São Paulo: Expressão Popular, 2004.

ARANHA, M. L. A.; MARTINS, M. H. P. Temas de filosofia. 2. ed. São Paulo: Moderna, 1998.

CANIELLES, A. S.; OLIVEIRA, A. R. A emancipação humana: uma abordagem a partir de Karl Marx. In: ENCONTRO BRASILEIRO DE EDUCAÇÃO E MARXISMO: Marxismo, Educação e 
Emancipação Humana, 5., 2011, Florianópolis. Anais... Disponível em <http://www.5ebem.ufsc.br/trabalhos/eixo_01/e01c_t003.pdf/>. Acesso em: 24 fev. 2013.

FORTES, R. V. Procedimento investigativo e forma expositiva em Marx - duas leituras: Lukács/Chasin. Verinotio, Belo Horizonte, v. 9, p. 73-105, 2009.

GRANEMANN, S. O processo de produção e reprodução social: trabalho e sociabilidade. 2009. Disponível em: <http://ucbweb2.castelobranco.br/webcaf/arquivos/12894/ 11251/3.1_O_processo_de_producao_e_reproducao_social_trabalho_e_sociabilidade.pd f>. Acesso em: 24 fev. 2013.

HOBSBAWM, E. Era dos extremos: o breve século XX - 1914-1991. Tradução de Marcos Santarrita. São Paulo: Companhia das Letras, 1995.

LESSA, S. A centralidade do trabalho na ontologia de Lukács. 1994.Tese (Doutorado em Ciências Sociais) - Instituto de Filosofia e Ciências Humanas da Universidade Estadual de Campinas, Campinas.

A centralidade ontológica do trabalho em Lukács. Revista Serviço Social \& Sociedade, São Paulo, v. 52, p. 7-23, 1996.

. A ontologia de Lukács: uma introdução. 1997. Disponível em:

<http://www.reocities.com/srglessa/Onto_de_Lukacs.pdf>. Acesso em: 9 nov. 2012.

MARX, K. A questão judaica. São Paulo: Moraes, 1991.

O capital. Rio de Janeiro: Civilização Brasileira, 1971. v. 1.

OFFE, C. Trabalho como categoria sociológica fundamental? In: Trabalho e sociedade. Rio de Janeiro: Tempo Brasileiro, 1989a. v.1,

- Trabalho e sociedade: problemas estruturais e perspectivas para o futuro da sociedade do trabalho. Rio de Janeiro: Tempo Brasileiro, 1989b. v. 1.

Trabalho e sociedade: problemas estruturais e perspectivas para o futuro da sociedade do trabalho. Rio de Janeiro: Tempo Brasileiro, 1991. v. 2

PAULO NETTO, J.; BRAZ, M. Econômica política: uma introdução crítica. 2. ed. São Paulo: Cortez, 2007. (Coleção Biblioteca Básica do Serviço Social, v. 1).

TAVARES, M. A. Acumulação, trabalho e desigualdades sociais. Brasília: CFESS/ABEPSS, 2009.

TERTULIAN, N. Uma apresentação a ontologia do ser social de Lukács. Revista Crítica Marxista, Campinas, n. 3, 1996. Disponível em <http://www.ifch.unicamp.br/criticamarxista/arquivos_biblioteca/3_Tertulian.pdf>. Acesso em: 26 fev. 2013. 
TONET, I. Educação, cidadania e emancipação humana. 2005. Disponível em: $<$ http://ivotonet.xpg.uol.com.br/arquivos/EDUCACAO_CIDADANIA_E_EMANCIPACAO_HU MANA.pdf>. Acesso em: 10 nov. 2012.

Trabalho associado e revolução proletária. 2010. Disponível em:

<http://ivotonet.xpg.uol.com.br/arquivos/TRABALHO_ASSOCIADO_REVOLUCAO_PROLET ARIA.pdf>. Acesso em: 12 nov. 2012. 